\title{
Economic impact of Patient's Own Medication use during hospitalisation: a multicentre pre-post implementation study
}

\author{
Loes J. M. van Herpen-Meeuwissen ${ }^{1,2}$ - Bart J. F. van den Bemt ${ }^{1,3,6} \cdot$ Hieronymus J. Derijks ${ }^{1,4}$. \\ Patricia M. L. A. van den Bemt ${ }^{5} \cdot$ Frank de Vries $^{6,7,8} \cdot$ Barbara Maat $^{2} \cdot$ Hein A. W. van Onzenoort ${ }^{9}$
}

Received: 23 August 2019 / Accepted: 28 October 2019 / Published online: 8 November 2019

(C) The Author(s) 2019

\begin{abstract}
Background Medication is frequently thrown away after a patient's discharge from hospital, with undesirable economic and environmental consequences. Because of the rising costs of healthcare, interventions to reduce medication wastage (and associated costs) are warranted. Using Patient's Own Medication during hospitalisation might decrease medication wastage and associated costs. Objective To study the economic impact of patient's own medication use on medication waste and hospital staff's time spent during hospitalisation. Setting In seven Dutch hospitals, of which university, teaching, general, and specialised hospitals, eight different hospital wards, surgical and medical, were selected. Method In this prospective pre-post intervention study data on the economic value of medication waste and time spent by healthcare professionals were collected for a 2 months period each. The economic value of medication waste was defined as the value $(€)$ of wasted medication per 100 patient days. For each ward, time spent on medication process activities was measured 10 times per staff member. The average time spent (in hours) on medication process steps (multiple activities) per staff member per 100 patients and associated salary costs were calculated for both periods. Main outcome measure The primary outcome of the study was the total economic value $(€)$ of wasted medication per 100 patient days. Results Implementation of Patient's Own Medication decreased the economic value of wasted medication by $39.5 \%$ from $€ 3983$ to $€ 2411$ per 100 patient days. The mean time spent on the total medication process was reduced with $5.2 \mathrm{~h}$ per 100 patients (from 112.7 to $104.4 \mathrm{~h}$ per 100 patients). We observed a shift in professional activities, as physicians and nurses spent less time on the medication process, whereas pharmacy technicians had a greater role in it. When time spent was expressed as salary; $€ 1219$ could be saved per 100 patients. Conclusions This study showed that 'Patient's Own Medication' implementation may have a positive economic impact, as the value of medication waste decreases, hospital staff devoted less time on the medication process, and staff deployment is more efficient.
\end{abstract}

Keywords Economic impact $\cdot$ Hospitalisation $\cdot$ Medication waste $\cdot$ Patient's own medication

Hein A. W. van Onzenoort

HvanOnzenoort@amphia.nl

1 Department of Pharmacy, Radboud University Medical Centre, Radboud Institute for Health Sciences, Nijmegen, The Netherlands

2 Department of Pharmacy, Elisabeth-TweeSteden Hospital, Tilburg, The Netherlands

3 Department of Pharmacy, Sint Maartenskliniek, Nijmegen, The Netherlands

4 Department of Pharmacy, Jeroen Bosch Hospital, 's-Hertogenbosch, The Netherlands

5 Department of Clinical Pharmacy and Pharmacology, University of Groningen, University Medical Center Groningen, Groningen, The Netherlands
6 Department of Clinical Pharmacy and Toxicology, Maastricht University Medical Center +, Maastricht, The Netherlands

7 Division of Pharmacoepidemiology and Clinical Pharmacology, Utrecht Institute for Pharmaceutical Sciences, Utrecht University, Utrecht, The Netherlands

8 Cardiovascular Research Institute Maastricht, Maastricht University Medical Centre, Maastricht, The Netherlands

9 Department of Clinical Pharmacy, Amphia Hospital, Breda, The Netherlands 


\section{Impact on practice}

- Patient's Own Medication use is a valuable intervention for decreasing cost of medication waste, time spent by healthcare professionals, and costs of associated salary.

- To successfully implement Patient's Own Medication use during hospitalisation, collaboration between hospital staff is a precondition.

- Patient's Own Medication implementation leads to a shift in professional activities in the current medication process by hospital staff.

\section{Introduction}

As healthcare costs are rising [1-3], interventions to reduce healthcare expenditures are warranted [4-8]. Medication represents a substantial and increasing proportion of healthcare budgets $[1,9,10]$. Unfortunately, a significant part of medication remains unused and is disposed of. In the U.K. alone, medication waste is estimated to cost the National Health Service $£ 300$ million per annum [11]. Moreover, it has a negative impact on both the economy and the environment $[12,13]$. Therefore, interventions to reduce medication waste are essential.

Medication waste occurs in both the ambulatory and acute care setting [8, 14-18]. While waste has been well studied in primary care [8, 14-16], little is known about the underlying reasons resulting in medication waste during hospitalisation [17, 18]. Medication substitution upon hospital admission and discharge, is probably an important driver of medication waste and results into direct and indirect unnecessary expenses. In most Western countries it is common practice that the hospital provides all inpatient medication, according to the hospital's formulary. Pans et al. observed that during hospitalisation $31 \%$ of medication used at home is substituted by the hospital [19]. Furthermore, when substitution is impossible, non-formulary medicines are purchased for individual patients. Both substitution and additional procurement of medication take a considerable amount of hospital staff's time and therefore, results in additional costs. At discharge, however, substituted medicines are resubstituted to patient's original medication by hospital staff. This in-hospital substitution policy takes significant time and leads to medication wastage as (opened) packages of medication are disposed of.

A promising intervention to reduce inpatient medication waste and medication-substitution related staff costs is the implementation of 'Patient's Own Medication' (POM; also known as Patient's Own Drug [POD]) use during hospitalisation [20]. Patients bring their own medication, provided by the community pharmacy, into the hospital when admitted. Consequently, substitution is no longer required. Therefore, POM use has the potential to improve the accuracy of admission orders and may decrease medication waste [21, 22]. Moreover, it may enhance opportunities for patient counselling and continuity of care between acute and primary care [23, 24]. Despite the possible advantages, POM use has not been implemented in routine health care. Concerns about the effects of POM use on medication safety and the uncertainty on economic benefits may limit its implementation [25]. As a result, POM is not used in standard care in the Netherlands and no study has been performed to evaluate the economic impact of POM use. This study, therefore, aims to explore the impact of POM use on the (1) economic value of wasted medication, (2) quantity of wasted medication, and (3) time spent by hospital staff and associated salary costs.

\section{Ethics approval}

The ethical review board CMO Arnhem-Nijmegen, the Netherlands, concluded that under Dutch law no ethical approval was required for this study (file number 2016-3088).

\section{Methods}

\section{Design}

A multicentre prospective intervention study with a pre-post design was conducted from August 2015 to June 2017. After a baseline 2-month pre-implementation period, the intervention (POM use during hospitalisation) was implemented and subsequently followed by a 2-month evaluation of the implementation.

\section{Study population}

The study was conducted at eight different wards in seven Dutch hospitals, of which three university, two teaching, one general, and one specialised hospital. We included the departments of Cardiology, Internal medicine, Haematology, Pulmonology, Medical Oncology, Orthopaedics, the combined wards Internal medicine/Gastroenterology/Geriatrics, and Gynaecology/Urology/Otorhinolaryngology. All patients admitted to the participating wards during the study were eligible for participation, if they already used medication before hospital admission or if medication was started during hospitalisation which was intended to be used at home. The use of individualised pre-packaged medication (either by an automated dispensing system or medication 
organiser box), without the possibility of bringing the original medication package to the hospital, was an exclusion criterion for participation in this study.

\section{Pre-intervention: standard care}

In the Netherlands, the current hospital medication process generally starts with medication reconciliation at admission. Based on this, physicians electronically order this medication, typically taking the hospital's formulary into account. When a medication is not on the hospital's formulary, medication is substituted to a different brand and/or a different pharmacotherapeutic class. In case a medicine cannot be substituted, it is procured for that individual patient.

Most Dutch hospitals use a floor stock distribution system. The stock comprises of the most frequently used medicines for the department and is regularly restocked. Whenever a medicine is not in stock, the medicine is dispensed from the pharmacy, where it is labelled and distributed to the requesting department. If the pharmacy does not have the medicine in stock, it places an order at a wholesaler or manufacturer. Though differences among hospitals and departments exist, medication cart filling is mostly performed for the upcoming $24 \mathrm{~h}$. During hospitalisation medication is administered by nurses, mostly by using Bar Code Medication Administration (BCMA). At discharge substituted medicines are resubstituted to the original medication by a physician. Newly initiated pharmacotherapy is prescribed by a physician as well. These prescriptions are filled by an outpatient pharmacy. All unused medication, including the specially procured medication, that has been dispensed during admission, is disposed of at patient's discharge. For an overview see Fig. 1.

\section{Intervention: POM use during hospitalisation}

In the intervention period patients were asked to bring their own medication in original packages to the hospital. In case of an acute hospitalisation, patient's relatives were asked to bring these within $24 \mathrm{~h}$. Medication reconciliation took place as in standard care. Thereafter, a physician electronically ordered patient's home medication without any medication substitution. Patient's own medication stock was checked by a nurse or pharmacy technician for completeness, shelf life, quality (by observation), and quantity. Thereafter, the medication was stored by patient name. Medication administration was performed by nurses, as in standard care. Newly started medication that should be continued at home and POM that ran out of stock were provided by the pharmacy and stored by patient name as well. At discharge POM was gathered, including newly started therapies, and handed over to the patient. Discontinued medication was disposed of.

\section{Data collection}

In both study periods, data were collected during 2 months The following ward characteristics were collected from the hospitals' general databases and annual reports: number of inpatient beds, mean number of admitted patients per month, mean length of stay (LOS), mean age of the patient population, and percentage acute admissions. All disposed medication was collected, identified, and quantified. The following medication characteristics were collected: name, dosage, quantity of individual units (e.g. number of tablets), unique identification code, Anatomical Therapeutic Code (ATC), and the price per unit.

\section{Pre-intervention}

\section{Medication origins for a patient}

- Floor stock Medication use for 1 day

- Hospital's stock Medication use for 2-7 days

- Individual purchases Whole packages

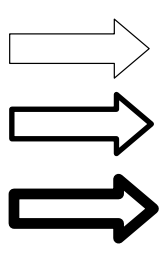

Medication at patient's discharge

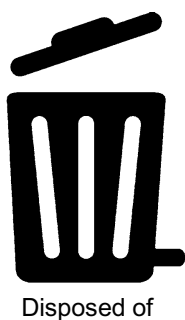

Disposed of

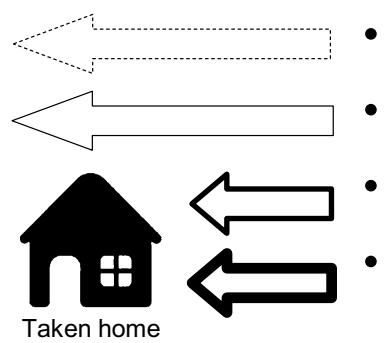

- $\quad$ Floor stock Medication use for 1 day Hospital's stock Medication use for 2-7 days Individual purchases Whole packages Patient's own medication Whole packages
Fig. 1 Expected medication waste due to the medication process. The thicker the arrow the more medication is expected to be wasted or taken home due to the quantity of medication assigned to a patient. During the pre-implementation period, all assigned patient's medica- tion is disposed of at discharge. It is to be expected that after implementation of Patient's Own Medication (POM) use, medication is not entirely disposed of at discharge as it is handed over to the patient 


\section{Medication price per unit}

To standardise medication prices, the price per unit was determined on the first of November 2017 using government set pharmacy retail prices, as listed in the G-Standard [26]. The G-Standard is the Dutch medication database, which is used by all parties in healthcare [26]. The G-Standard supports the different processes in healthcare, such as prescribing, dispensing, ordering, reimbursement, and clinical decision support [26]. This database lists the pharmacy retail price per unique medication identification code. When the unique medication identification code was not recognised by the database, for example because the product was no longer authorised, the retail price listed in de pharmacy system of the hospital where the product was disposed of was used as price per unit. Furthermore, if there was no retail price known, the net price per unit listed in the hospital pharmacy system was used. When both the retail and the net price were unknown, the study group manually searched for the retail price of the entire product group with the same generic prescription code and calculated the mean retail price per unit.

\section{Time spent by hospital staff}

Multiple groups of staff members play a role in the medication process, i.e. nurses, pharmacy technicians, physicians, pharmacists, and general (pharmacy or logistic) employees. Medication process activities were identified during the pre- and post-implementation process using the 'Value stream mapping' method [27]. All activities were part of one of the following process steps: medication reconciliation, ordering, distribution, dispensing, administration, inform patient, and patient's discharge. Activities performed within the medication process were measured at least ten times per ward per staff member by stopwatch timing. Activities could differ between wards and could change after POM implementation. If an activity did not change (same staff member, same activity) in the post-implementation period versus the standard care in the pre-implementation period, it was not measured again.

\section{Outcomes}

The primary outcome of the study was the economic value $(€)$ of wasted medication per 100 patient days. The secondary outcomes were the mean quantity of medication waste per 100 patient days and the time spent by hospital staff on the medication process per 100 patients including associated salary costs.

\section{Data analysis}

For each ward, the economic value $(€)$ of medication waste was calculated by dividing the total medication price per unit disposed of during the pre- and post-implementation period by the number of patient hospitalisation days (number of hospitalised patients on that ward times mean LOS) during the same period, and multiplied by 100 patients. In the same way the quantity of medication disposed of per 100 patient days was calculated as the total quantity of individual units disposed of. The mean time in hours (h) to perform activities within the medication process was calculated (if activities were measured $\geq 10$ times) as the time per hospital staff member per medication process step per 100 patients. Only "medication distribution" was not defined as time spent to perform the activity per 100 patients, as an employee distributes medication once daily for the total ward and not per patient. In that situation the mean time spent per day was calculated and reported separately. Furthermore, time spent was expressed as economic value by calculating the mean maximum salary per hospital staff member related to the time spent on the process steps. Because salary scales differ between types of hospitals a mean maximum salary based on these scales was calculated. Analyses were performed in Microsoft Excel (version 2006) using descriptive statistics.

\section{Results}

In total, eight wards participated, of which six were medical and two were surgical wards. Ward and patient characteristics are described in Table 1. All medical wards collected data on medication waste and all wards, with the exception of Ward B, collected data on time spent.

\section{Value of wasted medication}

The economic value of wasted medication per 100 patient days was $€ 3983$ and $€ 2411$ during the pre- and post-implementation period respectively (Fig. 2). There was a large variation in the value of wasted medication among the wards, both in the pre- and post-implementation period. Four wards showed a decrease in the value of wasted medication after implementation of POM, in one ward the opposite effect was observed, and one ward did not show a difference. After implementation of POM the total value of wasted medication per 100 patient days decreased with 39.5\% (€1572).

\section{Quantity of wasted medication}

The total quantity of medicines wasted was 1787 individual units per 100 patient days during the pre-implementation period and 2053 individual units per 100 patient days 
Table 1 Wards and patients characteristics during the pre- and post-implementation of Patient's own medication (POM) use study periods

\begin{tabular}{lllllllll}
\hline Ward & Type of ward & $\begin{array}{l}\text { Inpatient } \\
\text { beds (n) }\end{array}$ & $\begin{array}{l}\text { LOS } \\
(\mathrm{mean}, \\
\text { days) }\end{array}$ & $\begin{array}{l}\text { Acute } \\
\text { admissions } \\
(\%)^{\mathrm{a}}\end{array}$ & $\begin{array}{l}\text { Pre-POM } \\
\text { Admissions/ } \\
\text { month (n) }\end{array}$ & $\begin{array}{l}\text { Post-POM } \\
\text { Admissions/ } \\
\text { month (n) }\end{array}$ & $\begin{array}{l}\text { Pre-POM Mean } \\
\text { patient age (years; } \\
\text { SD) }\end{array}$ & $\begin{array}{l}\text { Post-POM Mean } \\
\text { patient age (years; } \\
\text { SD) }\end{array}$ \\
\hline A & Medical & 32 & 4.5 & 69 & 113 & 136 & $70.3(13.4)$ & $70.4(13.3)$ \\
B & Medical & 24 & 6.3 & 51 & 64 & 57 & $56.5(16.9)$ & $51.9(17.3)$ \\
C & Medical & 50 & 6.1 & 59 & 30 & 30 & $59.9(15.4)$ & $63.8(10.8)$ \\
D & Medical & 30 & 9.5 & 53 & 43 & 74 & $64.0(21.0)$ & $69.0(17.7)$ \\
E & Medical & 28 & 6.8 & 56 & 116 & 109 & $60.1(14.9)$ & $58.3(17.8)$ \\
F & Medical & 32 & 5.6 & 56 & 90 & 130 & $63.9(14.8)$ & $65.2(15.8)$ \\
G & Surgical & 77 & 3.4 & 11 & 306 & Unknown & $56.2(16.5)$ & Unknown \\
H & Surgical & 46 & 4.6 & 15 & 163 & 184 & $55.0(18.3)$ & $57.7(17.6)$ \\
\hline
\end{tabular}

LOS, Length of stay; Pre-POM, pre-implementation of Patient's own medication (POM) use study period; Post-POM, post-implementation of Patient's own medication (POM) use study period; SD, standard deviation

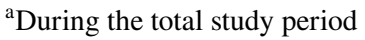

during the post-implementation period: an increase of $14.9 \%$ (Fig. 3). Four wards showed a decrease in quantity of wasted medication per 100 patient days, of which three wards also showed a decrease in value of wasted medicines per 100 patient days after POM use was implemented.

\section{Time spent by hospital staff}

A total of 2678 medication process activities were measured, of which 1729 pre- and 949 post-implementation. Of these 26 and 35 measurements were excluded respectively, as the activity was not measured ten times per staff member, resulting in 2617 measurements used for analysis. The medication process took $112.7 \mathrm{~h}$ per 100 patients in the pre-implementation versus $104.4 \mathrm{~h}$ per 100 patients in the post-implementation period. Moreover, POM use resulted in a $5.2 \mathrm{~h}(4.6 \%)$ decrease per 100 patients in time spent by hospital staff. Furthermore, a shift in professional activities among staff members was observed. A reduction of time spent on medication process activities when POM use was implemented was accomplished for physicians $(-11.3 \mathrm{~h} / 100$ patients) and nurses ( $-16.2 \mathrm{~h} / 100$ patients). Pharmacy technicians had a more substantial role in the new medication process, which resulted in a increase in time spent of $22.2 \mathrm{~h}$ per 100 patients (Table 2). When time spent was translated to salary costs, the saved time and the shift in deployment resulted in net savings of $€ 1219$ per 100 patients.

The daily time spent on the distribution of medication by pharmacy technicians and general pharmacy or logistic employees was similar before $(0.1 \mathrm{~h})$ and after $(0.1 \mathrm{~h})$ implementation of POM use.

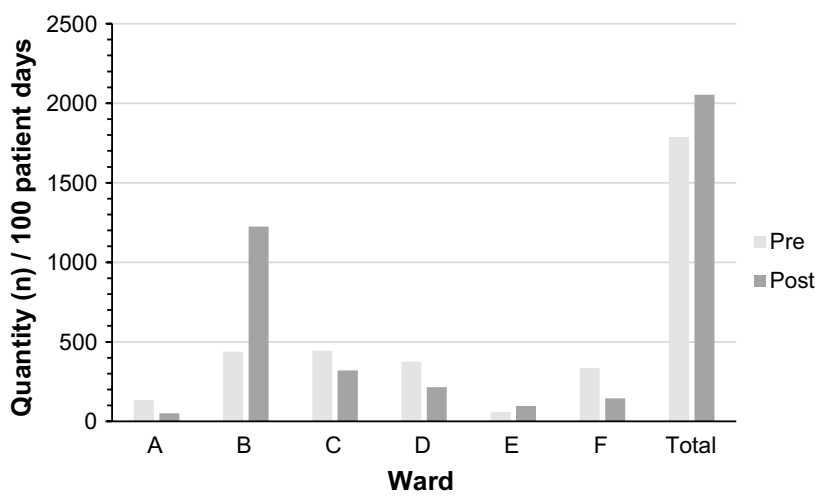

Fig. 3 The quantity ( $\mathrm{n}=$ individual units) of wasted medication per 100 patient days during the pre- and post-implementation of Patient's Own Medication (POM) use during hospitalisation on the participating medical wards 
Table 2 Mean time spent (in hours $[\mathrm{h}]$ ) to perform an activity in the medication process per medication process step per staff member per 100 patients during the pre- and postimplementation of Patient's Own Medication (POM) use during hospitalisation

\begin{tabular}{llccc}
\hline Medication process step & Staff member & $\begin{array}{l}\text { Pre-POM } \\
\text { (h/100 patients })\end{array}$ & $\begin{array}{l}\text { Post-POM } \\
(\mathrm{h} / 100 \text { patients })\end{array}$ & $\begin{array}{l}\text { Differ- } \\
\text { ence }(\mathrm{h} / 100 \\
\text { patients }\end{array}$ \\
\hline Medication reconciliation & Pharmacy technician & 12.6 & 12.4 & -0.2 \\
& Physician & 7.4 & 5.5 & -1.9 \\
& Nurse & 6.2 & 3.8 & -2.4 \\
Ordering & Physician & 6.0 & 6.0 & 0.0 \\
& Pharmacist & 3.0 & 3.0 & 0.0 \\
& Pharmacy technician & 0.5 & 17.4 & +16.9 \\
& Nurse & 22.1 & 7.6 & -14.5 \\
Dispense & Pharmacy technician & 7.4 & 7.4 & 0.0 \\
& Nurse & 6.9 & 5.0 & -1.9 \\
Medication administration & Nurse & 4.7 & 5.2 & +0.6 \\
Inform patient & Pharmacy technician & 5.0 & 9.3 & +4.3 \\
& Physician & 7.0 & 2.5 & -4.5 \\
Patient's discharge & Pharmacy technician & 10.2 & 11.4 & +1.2 \\
& Physician & 10.7 & 5.8 & -4.8 \\
& Nurse & 3.1 & 5.1 & +2.0 \\
Total & & 107.4 & -5.2 \\
\hline
\end{tabular}

Pre-POM, pre-implementation of Patient's own medication (POM) use study period; Post-POM, postimplementation of Patient's own medication (POM) use study period

\section{Discussion}

The implementation of POM use during hospitalisation showed a total potential saving of more than $€ 1500$ per 100 patient days on medication waste costs. Nevertheless, an increase in the quantity of individual medication units disposed of was shown. The POM process resulted in a decreased time spent by hospital staff of $5.2 \mathrm{~h}$ per 100 patients (4.6\%) on the medication process when compared to standard care. A shift in responsibilities between staff members was shown, resulting in net savings of over $€ 1200$ per 100 patients.

This study was the first study that investigated the effect of implementing POM use on economic waste in hospitalised patients. POM use has recently been investigated in a Danish setting, but instead of focussing on waste Houlind et al. studied medication expenditures [28]. They concluded that implementing POM use did not lead to a significant difference between medication cost per patient when compared to the traditional medication system ( $\$ 2.03$ [95\% confidence interval -0.57 to 4.63 ] $p=0.131$ ) [28]. Although medication cost was not subject to research in our study, it is expected that POM use will decrease hospitals' medication expenditures as less medicines should be ordered at the wholesaler because patients bring their own.

We observed considerable heterogeneity between wards in disposed of medication and related costs with the introduction of POM. There are several possible reasons why not all wards showed a decrease in the value and quantity of disposed of medication. Firstly, during the post-implementation period staff might not have adapted to the new medication process sufficiently. Consequently, staff might erroneously ordered outpatient medication packages for patients that were not eligible for POM use and forgot to endow home medication to the patient at discharge. These packages were all disposed of at discharge, and resulted in more medication waste during the post-implementation period. It is expected that if the medication process was performed according to protocol, less medication would have been disposed of. Secondly, it could be that more complex patients were admitted on the wards in the post-implementation period as study periods were randomly chosen. Treating complex patients may lead to additional changes in therapeutic therapy, resulting in starting and stopping medication more frequently and consequently increasing the quantity of medication being wasted.

To implement POM use during hospitalisation we anticipated that the current medication process required several adaptations to fit the new way of working. As a consequence, professional activities were assigned to other staff members. We observed, indeed, a shift in performer resulting in a net saving of time spent. Two medication process steps, ordering and medication administration, took hospital staff more time when POM use was implemented. This additional time spent may be explained by the fact that time measurements took place directly after implementation. As staff may not have completely adopted the new medication process deployment yet; because of the shift in tasks, activities may have taken more time. It is to be expected that new tasks will be completed more rapidly when habituation occurs. 
Consequently, the results of this study on time spent may be an overestimation.

The implementation of POM use is challenging due to needed adaptations in the medication process. It requires changes in: the role of patients and staff members, health care finance, hospital ICT systems, medication logistics, and hospital's medication stock. Moreover, POM use raises some concerns as it may introduce (other types of) medication errors. For example the quality of the medication cannot be guaranteed, medication packages may be less recognizable to nursing staff, and BCMA is not always possible. It is, therefore, important to continuously evaluate this new medication process and address the expected safety aspects of POM use [29].

Nevertheless, POM use initiates several opportunities as well. It has been suggested that POM use gives better opportunities for patient counselling and stimulates continuity of care [23, 24]. Moreover, several studies found that bringing POM into the hospital prevents medication errors at admission and after hospitalisation, and it improves the quality of medication used at home [21-23, 30]. Due to POM use during hospitalisation, patients may recognise their medication better which could have a positive effect on adherence at home, which is known to be a problem [31]. Lastly, POM use facilitates the opportunity of self-administration of medication by hospitalised patients. Future studies, therefore, should focus on the effect of POM use during hospitalisation on medication safety and the applicability of self-administration of POM.

A strength of this study is our study population which reflects the Dutch hospital patient population well. Those hospitals included, together account for a tenth of the total number of hospital admissions yearly in the Netherlands [32]. Moreover, the mean LOS and mean age of the population are representative $[32,33]$.

This study has limitations. The participating wards did not include all patients who were able to participate in POM schemes. Moreover, we were unable to address the proportion of admitted patients who participated in POM schemes on the included wards. The effects of POM use in this study, therefore, may have been underestimated as the total ward was measured. Another potential limitation was the relatively short study period of 2 months for each phase. This may have limited the applicability of results found. Nevertheless, other studies on medication waste were conducted for shorter periods [30, 34]. In addition, by including different ward types, hospitals, and seasons, the factors that influenced medication waste varied. There were less time measurements in the post-implementation period. This was due to a conscious choice in the set-up of the time measurements: activities that did not change were not measured again. This was chosen because the time measurements were very time consuming and were conducted by healthcare professionals on top of their normal care activities. This may have led to bias. Lastly, the post-implementation period started directly after the implementation. This may have resulted in unintended medication waste and additional time spent on the medication process as a consequence of limited habituation. Therefore, the results of this study may underestimate the economic impact of and overestimate the time spent on POM use during hospitalisation.

In conclusion, POM use could reduce medication waste cost by more than $€ 1500$ per 100 patient days. We did not find a positive effect on the quantity of wasted medication. POM use took less of hospital staff time spent, namely: $5.2 \mathrm{~h}$ per 100 patients; and in terms of salary more than $€ 1200$ could be saved per 100 patients. It is expected that our results underestimate the true effects when POM use is fully implemented. Furthermore, POM use may lead to a more efficient deployment of hospital staff.

Acknowledgements Dr. E Vasbinder (Groene Hart Ziekenhuis), Drs. E. Sportel (Medisch Spectrum Twente), and Dr. A. Scheepers-Hoeks (MUMC +)

Funding Dutch Ministry of Health, Welfare and Sport, the Hague.

Conflicts of interest LHM: none; BB: none related to current study; HD: none; PB: none related to current study; FV: supervises Ph.D. students who are employed by F. Hoffmann La Roche Ltd. (Basel, Switzerland and Welwyn Garden City, UK). He has not received any reimbursements or fees and the $\mathrm{Ph}$.D. topics are not related to the current study; BM: none; HO: none.

Open Access This article is distributed under the terms of the Creative Commons Attribution 4.0 International License (http://creativeco mmons.org/licenses/by/4.0/), which permits unrestricted use, distribution, and reproduction in any medium, provided you give appropriate credit to the original author(s) and the source, provide a link to the Creative Commons license, and indicate if changes were made.

\section{References}

1. Centraal bureau voor de statistiek. Zorguitgaven stijgen in 2017 met 2,1 procent. 2018. https://www.cbs.nl/nl-nl/nieuws/2018/22/ zorguitgaven-stijgen-in-2017-met-2-1-procent. Accessed 25 March 2019

2. OECD. Health at a Glance 2017: OECD Indicators. Health at a Glance. Paris: OECD Publishing; 2017. p. 2017.

3. Zorgautoriteit N. Uitgaven aan dure geneesmiddelen stijgen naar 2,1 miljard. 2019. https://www.nza.nl/actueel/nieuws/2019/01/30/ uitgaven-aan-dure-geneesmiddelen-stijgen-naar-21-miljard. Accessed 20 March 2019.

4. National Health Council. Policy recommendations for reducing health care costs. 2017.

5. Schippers EI. Plan van Aanpak Het tegengaan van Verspilling in de Zorg. Den Haag: Ministerie van Volksgezondheid, Welzijn en Sport; 2013

6. National Institute for Health and Care Excellence. Cost-saving guidance. https://www.nice.org.uk/about/what-we-do/into-pract ice/cost-saving-guidance. Accessed 25 March 2019. 
7. Ferguson B. Cost savings and the economic case for investing in public health. Public Health England. 2018. https://publicheal thmatters.blog.gov.uk/2018/04/09/cost-savings-and-the-econo mic-case-for-investing-in-public-health/. Accessed 25 March 2019.

8. National Health Service. Only order what you need. Dynamic Advertising Group 2019. http://www.medicinewaste.com/. Accessed 21 Nov 2018.

9. Hartman M, Martin AB, Espinosa N, Catlin A, The National Health Expenditure Accounts T. National health care spending in 2016: spending and enrollment growth slow after initial coverage expansions. Health Aff (Millwood). 2018;37(1):150-60. https:// doi.org/10.1377/hlthaff.2017.1299.

10. Zorginstituut Nederland. Zorginstituut: uitgaven geneesmiddelen stijgen. 2018. https://www.zorginstituutnederland.nl/actueel/ nieuws/2018/04/17/zorginstituut-uitgaven-geneesmiddelen-stijg en. Accessed 20 March 2019.

11. Trueman PLK, Blighe A, Meszaros A, Wright D, Glanville J. Evaluation of the scale, causes and costs of waste medicines. London: York Health Economics Consortium and School of Pharmacy University of London; 2010.

12. Kümmerer K. Pharmaceuticals in the environment. Annu Rev Environ Resour. 2010;35(1):57-75. https://doi.org/10.1146/annur ev-environ-052809-161223.

13. Yves Chartier JE, Pieper U, Prüss A, Rushbrook P, Stringer R, Townend W, Wilburn S, Zghondi R. Safe management of wastes from health-care activities. Malta2014.

14. Bekker CL, Melis EJ, Egberts ACG, Bouvy ML, Gardarsdottir $\mathrm{H}$, van den Bemt BJF. Quantity and economic value of unused oral anti-cancer and biological disease-modifying anti-rheumatic drugs among outpatient pharmacy patients who discontinue therapy. Res Soc Admin Pharm: RSAP. 2019;15(1):100-5. https://doi. org/10.1016/j.sapharm.2018.03.064.

15. Bekker CL, van den Bemt BJF, Egberts ACG, Bouvy ML, Gardarsdottir $\mathrm{H}$. Patient and medication factors associated with preventable medication waste and possibilities for redispensing. Int J Clin Pharm. 2018;40(3):704-11. https://doi.org/10.1007/s1109 6-018-0642-8.

16. Vogler S, de Rooij R. Medication wasted-contents and costs of medicines ending up in household garbage. Res Soc Admin Pharm: RSAP. 2018;14(12):1140-6. https://doi.org/10.1016/j. sapharm.2018.02.002.

17. World Health Organization. Health-care waste. 2018. https://www. who.int/news-room/fact-sheets/detail/health-care-waste. Accessed 20 March 2019.

18. Pore SM. Pharmaceutical waste from hospitals and homes: need for better strategies. Indian J Pharmacol. 2014;46(4):459-60. https ://doi.org/10.4103/0253-7613.135969.

19. Pans SJA, Hugtenburg JG, Berger-de Jong IEJ, Voorhorst FJ, Janssen MJA. Medicatiewijzigingen tijdens ziekenhuisverblijf op de afdelingen orthopedie en chirurgie. PW Wetenschappelijk Platform. 2008;2(4):80-5.

20. Newman C. How to reduce medicines waste. Clin Pharm. 2011;3:26.
21. Chan EW, Taylor SE, Marriott JL, Barger B. Bringing patients' own medications into an emergency department by ambulance: effect on prescribing accuracy when these patients are admitted to hospital. Med J Aust. 2009;191(7):374-7.

22. Dutton K, Hedger N, Wills S, Brown D, Davies P. Prevent medication errors on admission. Int J. 2003;8:128-37.

23. Lummis H, Sketris I, Veldhuyzen van Zanten S. Systematic review of the use of patients' own medications in acute care institutions. J Clin Pharm Ther. 2006;31(6):541-63. https://doi.org/10.111 1/j.1365-2710.2006.00773.x.

24. James RC, Leong CK, Martin RC, Plumridge RJ. Patient's own drugs and one-stop dispensing: improving continuity of care and reducing drug expenditure. J Pharm Pract Res. 2008;38(1):44-6.

25. Lummis H, Sketris I. Use of Patients' Own Medications in Canadian Hospitals: a national survey. Can J Hosp Pharm. 2008;61(2):114-22.

26. Dutch Association for the Advancement of Pharmacy. The G-Standard: the medicines standard in healthcare https://www. knmp.nl/producten/gebruiksrecht-g-standaard/informatie-overde-g-standaard/the-g-standaard-the-medicines-standard-in-healt hcare. Accessed 16 April 2019.

27. Rother M, Shook J. Learning to see: value stream mapping to add value and eliminate Muda. 1.3 ed. Cambridge, MA: Lean Enterprise Institute; 1999.

28. Houlind MB, McNulty HBO, Treldal C, Andersen SL, Huneck Haupt T, Petersen J, et al. One-stop dispensing: hospital costs and patient perspectives on self-management of medication. Pharmacy. 2018. https://doi.org/10.3390/pharmacy6020046.

29. Joint Commission International. Joint Commission International Accreditation Standards for Hospitals. 6th ed. Oak Brook, IL, USA; 2017.

30. Asare AF, Safdar A, Tomlin S, Heyes P. Cost savings from using patients' own drugs in a paediatric hospital. Clin Pharm. 2009;1:489.

31. Sabaté E. Adherence to long term therapy: evidence for action. Geneva2003.

32. Panteia. Kengetallen Nederlandse Ziekenhuizen 2014. Utrecht2016.

33. Statistiek CBvd. Ziekenhuisopnamen naar leeftijd en geslacht. 2012. https://www.volksgezondheidenzorg.info/onderwerp/zieke nhuiszorg/cijfers-context/gebruik\#node-ziekenhuisopnamen-naarleeftijd-en-geslacht. Accessed 17 July 2019.

34. Tisdall J, Edmonds M, McKenzie A, Snoswell CL. Pharmacyled ward-based education reduces pharmaceutical waste and saves money. Int J Pharm Pract. 2019. https://doi.org/10.1111/ ijpp. 12528.

Publisher's Note Springer Nature remains neutral with regard to jurisdictional claims in published maps and institutional affiliations. 